\title{
Effects of Virtual Reality Intervention on Neural Plasticity in Stroke Rehabilitation: A Systematic Review
}

Jie Hao

University of Nebraska Medical Center, jie.hao@unmc.edu

Haoyu Xie

University of Nebraska Medical Center

Kimberly Harp

University of Nebraska Medical Center, kimberly.harp@unmc.edu

Zhen Chen

First Rehabilitation Hospital of Shanghai, China

Ka-Chun Siu

University of Nebraska Medical Center, kcsiu@unmc.edu

Tell us how you used this information in this short survey.

Follow this and additional works at: https://digitalcommons.unmc.edu/cahp_pt_pres

Part of the Physical Therapy Commons

\section{Recommended Citation}

Hao, Jie; Xie, Haoyu; Harp, Kimberly; Chen, Zhen; and Siu, Ka-Chun, "Effects of Virtual Reality Intervention on Neural Plasticity in Stroke Rehabilitation: A Systematic Review" (2021). Posters and Presentations: Physical Therapy. 30.

https://digitalcommons.unmc.edu/cahp_pt_pres/30

This Poster is brought to you for free and open access by the Physical Therapy at DigitalCommons@UNMC. It has been accepted for inclusion in Posters and Presentations: Physical Therapy by an authorized administrator of DigitalCommons@UNMC.For more information, please contact digitalcommons@unmc.edu. 


\section{Effects of Virtual Reality Intervention on Neural Plasticity in Stroke Rehabilitation: A Systematic Review}

Jie Hao ${ }^{1 *}$, Haoyu Xie ${ }^{1}$, Kimberly Harp ${ }^{1}$, Zhen Chen ${ }^{2}$ and Ka-Chun Siu ${ }^{1 * *}$ UNIVERSITY OF NEBRASKA MEDICAL CENTER"
${ }^{1}$ University of Nebraska Medical Center, Omaha, Nebraska, United States; ${ }^{2}$ The First Rehabilitation Hospital of Shanghai, China
PRESENTED AT:

World

Physiotherapy Congress2021 online

\section{Introduction}

Virtual reality (VR) has been increasingly adopted in medicine for recent decades, and this emerging technology has shown promising results in stroke rehabilitation.

As a computer-generated simulation technology, VR creates an enriched and gamified environment [See right figures], facilitate task-specific training and provides multimodal feedback to augment the functional recovery by driving the experience-dependent neural plasticity.

Currently, a majority of research focuses on effects of VR on functional recovery and clinical outcomes; understanding how the neural underpinnings of those effects are critical for optimizing the use of VR technology for patient care.

\section{Purpose}

This systematic review aimed to summarize the current literature regarding the effects of VR-based rehabilitation on neural changes in stroke patients.

\section{Methods}

Six literature databases were searched, including Medline via Ebsco, Embase, PsycoINFO, IEEE Explore, Cumulative Index of Nursing and Allied Health, and Scopus.

The results were limited to articles published in English and between 2000 to 2020 .

This review was registered at the PROSPERO (ID: CRD42020196405).

\section{Results}

A total of 217 records were identified from six databases, and 26 studies were

finally included in this systematic review. Six common neural plasticity patterns were summarized below:

\begin{tabular}{|cl|}
\hline \multicolumn{2}{|c|}{ VR-induced Neural Plasticity in Stroke Rehabilitation } \\
\hline$\checkmark$ & Improved interhemispheric balance \\
$\checkmark$ & Enhanced cortical connectivity between functional regions \\
$\checkmark$ & Increased representation mapping of the affected limb \\
$\checkmark$ & Improved neural plasticity was correlated to enhanced functional measures \\
$\checkmark$ & Increased activation of regions in the frontal cortex \\
$\checkmark$ & The mirror neuron system may be involved in VR intervention \\
\hline
\end{tabular}
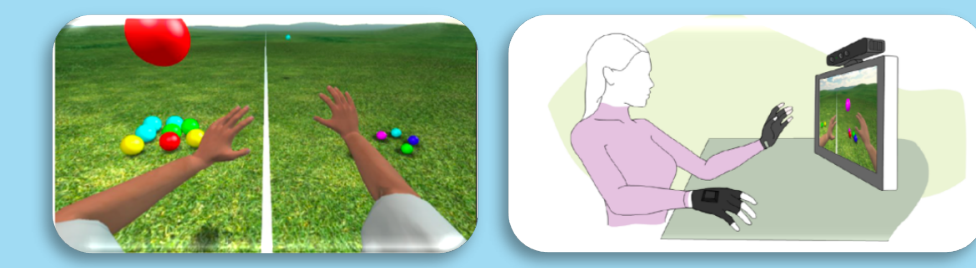

6. Implications

This review prompts the systematic understanding of the neurophysiological mechanisms of VR-based stroke rehabilitation, provides the emerging evidence for ongoing innovation of VR system and its application in stroke rehabilitation.

References 1. Hao J, Xie HY, Harp K, Chen Z, Siu KC. The effects of virtual reality on neural plasticity in stroke rehabilitation: a systematic review. Achieves of Physical Medicine and Rehabilitation. (Under review)

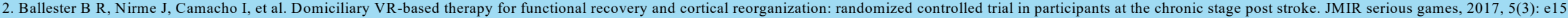

